\title{
Data workflow for generating static geological model platform for petroleum prospect re-evaluation of Wytch Farm field, Wessex Basin, South Coast, United Kingdom
}

\section{Olawale Olakunle OSINOWO ${ }^{1,2}$ (1)}

${ }^{1}$ Department of Earth Science and Engineering, Imperial College London, United Kingdom; e-mail: olawale.osinowo13@alumni.imperila.ac.uk

${ }^{2}$ Department of Geology, University of Ibadan, Ibadan, Nigeria; e-mail: wale.osinowo@ui.edu.ng

\begin{abstract}
The analyses and interpretation of the old existing 3D seismic and well log data of Wytch Farm field, Wessex Basin, south coast of the United Kingdom provided relevant information employed to generate static geological model platform. The platform which is requisite for building and distributing petrophysical and production data across the field could be useful for simulating the field's performance, history matching as well as generate future prediction/forecast needful to establish the reasons for the early water breakthrough and sudden production decline from a peak value of 115,000 bbl/day in 1997 to the present production rate of less than 19,000 bbl/day. Six major faults which extend throughout the entire length of the field and five horizon surfaces which correspond to the top of Greensand, Combrash, Mercia mudstone and the top and base of Sherwood Formations aided the generation of the static geological model platform across the Wytch Farm field. The volume of delineated saturated reservoir rock lying above the Oil Water Contact (OWC) and enclosed within fault assisted anticlinal structures indicate a Gross Rock Volume (GRV) of 2,007,000,000 $\mathrm{m}^{3}$ and thus suggest that Wytch Farm field may likely still hold hydrocarbon potential beyond the present daily production rate. This potential could be unlocked through adequate reservoir management that requires detailed information such as could be generated from static geological model of the field.
\end{abstract}

Key words: static geological model, early water breakthrough, hydrocarbon prospect re-evaluation, production decline, Sherwood reservoir

\section{Introduction}

Wytch Farm field which is one of the three oil fields (Wareham and Kimmeridge oil fields) in the Wessex Basin and lies beneath Poole Harbour and 
the Isle of Purbeck in southeast Dorset, west of London, south coast, of the United Kingdom (Fig. 1), is the largest known onshore oilfield in western Europe (Underhill and Stoneley, 1998). The field straddles both the onshore and offshore blocks with approximately one half of the reserve located in the offshore block of the field (McKie et al., 1998). The development of oil and gas potential of the Wytch Farm field which was initiated by the occurrence of several oil seepages and inflammable gas along the Dorset coast began in 1934 with several field studies to map the surface evidences of anticlinal structures as well as analyse the observed oil seepages in order to establish its relevance as a pointer to hydrocarbon finds (Stoneley, 1982; Underhill and Stoneley, 1998).

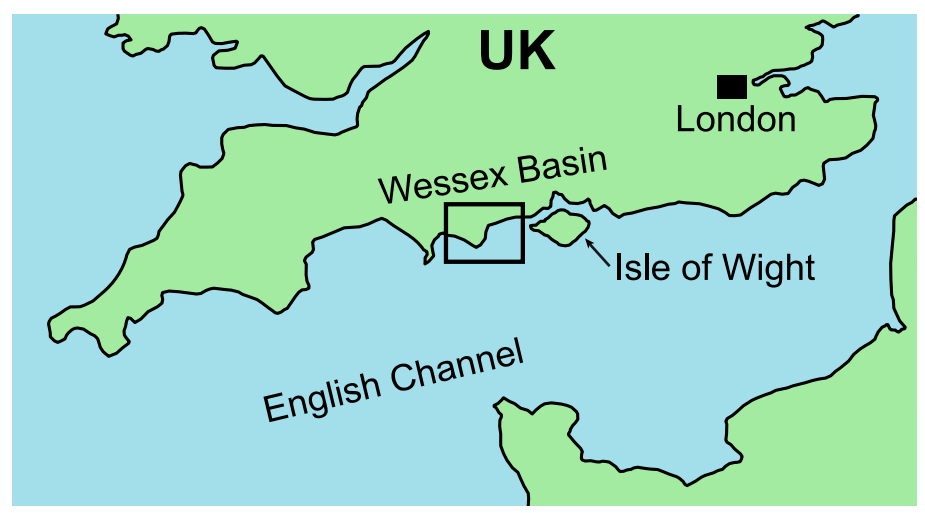

Fig. 1. Location map of the study area.

Seismic data acquisition campaign carried out between 1970 and 1972 provided subsurface information for the identification of subsurface structures as well as confirms the subsurface extension of exposed anticlinal structures which were isolated as one of the favourable structures to trap hydrocarbon within reservoirs. Further development of the petroleum lead through the drilling of first exploratory well in 1973 into the Bridport reservoir near Wytch Farm, where the field got its name, confirmed the occurrence of $51 \mathrm{~m}$ column of 37.2 API oil in the $53 \mathrm{~m}$ thick Bridport Sandstone, having proven reserve that could produce at $600 \mathrm{bbl} / \mathrm{d}$ (Underhill and Stoneley, 1998; Johnson et al., 2012). Additional exploratory wells drilled into the Bridport reservoir which include four (4) other exploratory wells and eight (8) development wells between 1978 and 1979 saw crude oil produc- 
tion rose to $1000 \mathrm{bbl} / \mathrm{d}$. Another exploratory well into the deeper Sherwood Sandstone reservoir also confirmed $60 \mathrm{~m}$ column of 40 API oil in the $160 \mathrm{~m}$ thick Sherwood Sandstone with reserve that is able to produce at $4000 \mathrm{bbl} / \mathrm{d}$. Several other developmental activities, including drilling and production from shallower limestone reservoir of the Frome Clay Formation together with the development of the offshore section of the field saw production peaked to 115,000 bbl/d by the end of 1997. However, Wytch Farm field was reported to experience early water breakthrough which has been attributed to the occurrence of en echelon faulting which probably formed pathways that allowed early water breakthrough. This reduced the production drastically from the peak $115,000 \mathrm{bbl} / \mathrm{d}$ to the current daily production below 19,000 bbl/d (Hinde, 1980; Colter and Havard, 1981; Buchanan, 1998; Johnson, et al., 2012). This study therefore aims at re-evaluating the hydrocarbon prospectively of the field through a requested data workflow for the analyses of the available 3D seismic and well log data. Thus generating a static model that could be employed to carry out reservoir simulation and thereby determine the performance of the field from production to the present as well as project beyond the present in order to maximize hydrocarbon production from the reservoirs.

\section{Geology of the study area}

The Wessex Basin, bounded in the north by the London Platform (LondonBrabant massif), in the south by Central Channel High (Fig. 1) and limited in the west and southwest by the Cornubian and Armorican Massifs, respectively, (Underhill and Stoneley, 1998) has been variously reported to begin with strong, localized differential vertical movement during the PermoTriassic rifting. The event was documented to affect most of northwestern Europe and continued through the Jurassic and early Cretaceous (Hawkes et al., 1998). The combination of rifting and associated extensional collapse of deep seated late Carboniferous Variscan thrusts with subsequent subsidence which was accompanied by continuing gentle thrust faulting along persistent lines of weakness created series of linked intracratonic basins that formed in the Jurassic and early Cretaceous. The series of events was also reported to be associated with intermittent growth on deep-seated listric normal faults and roll-over anticlines on their downthrown sides which together 
with general basin subsidence influenced sediment accumulation during the early Cretaceous. Several authors (e.g. Arkell, 1947; Smith and Curry, 1975; Stoneley, 1982; Smith and Hatton, 1998; Underhill and Stoneley, 1998) report that the basin reaches stability in the late Cretaceous. This was later followed by tectonic inversion in the Miocene when northward compressive movement along the formal normal faults slip caused reversed movement along the fault plane in opposite direction. This resulted in the initial down slip movement of the faulted blocks with widespread visible evidences occurring in south-eastern England and northern Europe (Beeley and Norton, 1998).

The structural framework of the basin (Fig. 2) reflects the imprint of the rifting and other tectonic events that occurred during the evolution of the basin. Generally the basin is characterised by major thrust faults, folding as well as regional magmatic and metamorphic activities. The structural frame of the Wessex Basin present an extensive, east-west trending gently dipping anticline which has been divided into north-dipping blocks by early Cretaceous extensional faults (Stoneley, 1982; McKie et al., 1998). The extensional faults include inter-basin (Purbeck-Isle of Wight) and intra-basin

\section{S}

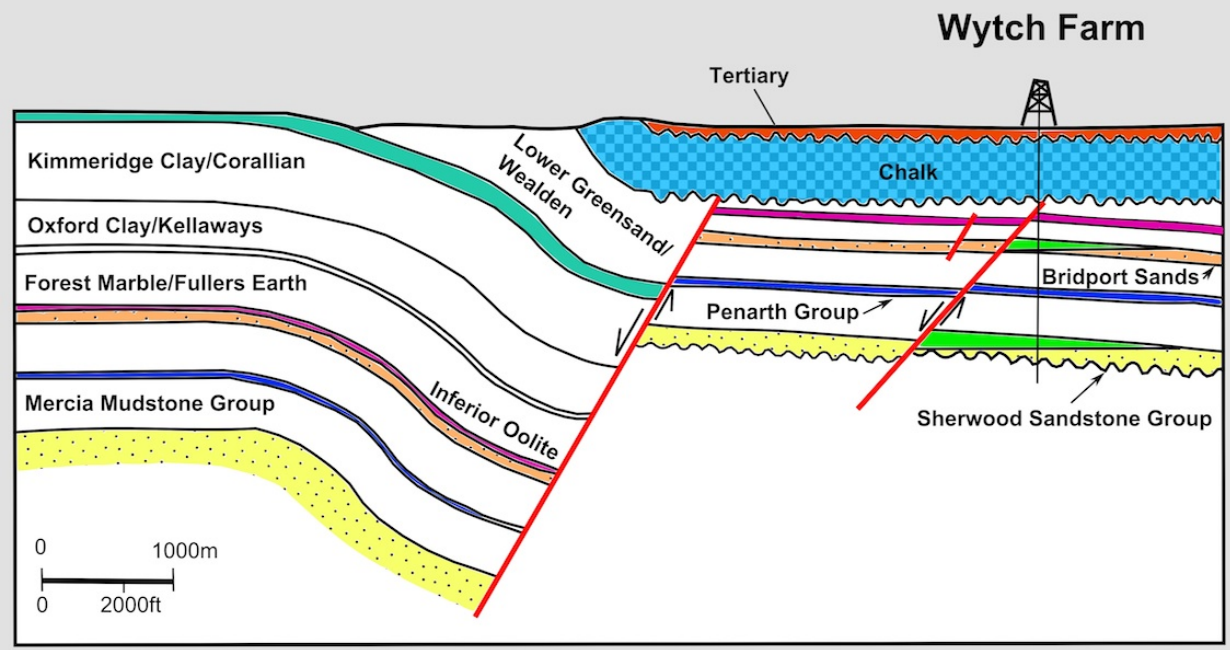

Fig. 2. North-south cross section of Wytch Farm Oil field showing the stratigraphic and structural framework of the study area (Colter and Havard, 1981). 
(Wardour and Portsdown) fault systems (Dearman, 1963).

The Wytch Farm field is approximately $18 \mathrm{~km}$ long and $3 \mathrm{~km}$ wide (Zheng et al., 200\%), it is characterised by faulted and folded structures that resulted from rifting and extensional thrust faulting that affected the whole Wessex Basin in the early Cretaceous (Bowman et al., 1993). The field comprises of east-west trending gently dipping anticline divided by series of northerly dipping faulted blocks generated during early Cretaceous extensional thrust faulting in the entire Wessex Basin (Zheng et al., 200\%; Hogg et al., 1999; McKie et al., 1998).

Several workers have attempted to reconstruct the stratigraphy of the basin describing various rocks types from both field observations and borehole information (e.g. Dingwall, 1971; Colter and Havard, 1981; Butler, 1998). The major lithologic units that have been documented include the Permian Rotliegend Sandstone with the overlying Red Marls/evaporates and Triassic Sherwood Sandstone together with the overlying Mercia Mudstone Groups which belong to the early plate separation sequences of events (Strong and Milodowski, 1987). The deposition of the Liassic Marine Mudstones, the Kimmerdge Clay, Shallow Marine Shoreface Bridport Sandstone and the Carbonate rocks (Combrash and Forest Mable) documented the Atlantic plate separation in the early to late Jurassic. The event of the Biscay plate separation was documented by the deposition of the shallow Marine Greensand and Chalk. The Petroleum system of the Wytch Farm field consist of Liassic Marine Mudstones source rock that through upward migration charged the three reservoir rock within the basin, namely; Sherwood, Bridport and the Frome Clay, with the Sherwood being the main reservoir (Bowman et al., 1993; Hawkes et al., 1998; Morris, 2005). The rollover anticlinal structures which are sometimes assisted by north dipping fault systems (Fig. 2) provided the necessary traps that constrain the hydrocarbon within the reservoir rocks while the Mercia Mudstone Group formed the cap rock that prevented upward migration of the trapped hydrocarbon within the reservoir systems (Warrington et al., 1980). Other potential source rock such as the Kimmeridge Clay also exists, but it is immature. Combrash and Forest Mable are tight carbonate reservoir with potential hydrocarbon reservoir in the basin, but require hydraulic stimulation to release the locked hydrocarbon within the reservoir (Dranfield et al., 1987; Underhill and Stoneley, 1998). 


\section{Materials and methods}

The various techniques employed to interprete the 3D Wytch Farm seismic data for the purpose of generating static geologic model is presented in this section. Seismic data interpretation involved mapping of the available fault structures as well as the horizons of interest. The horizons of interest were delineated from available exploratory wells in the field as those formation tops showing significant hydrocarbon shows from well log signatures and core samples. The adopted appraoch was to interprete the well logs as well as integrate core information to delineate the well tops corresponding to the geological formations with hydrocarbon shows. The top and the base of the reservoirs were identified as well as other overburden formations that could be significant to the hydrocarbon potential of the field. However, because seismic record is usually presented in time while the well log data are calibrated in depth, there is the need to bring the two of them to the same domain. Usually, the well information is converted to time so that the interpreted horizons can be posted in time on the seismic data for horizon mapping. To achieve a good well to seismic tie, a Time Depth Relation (TDR) with which to convert the well surfaces to time was generated. A simplfied geophysical workflow was adopted to achieve this. The well log data and checkshot data were first Quality Checked (QC) and despiked of spiky and out ranged data that bears no geologic significance. The resultant data were employed to generate TDR with which to tie the well data to the seismic record.

Sonic well log data which provides a measure of the travel time of sound wave through the rock in the immediate environment of the well bore were quality checked and despiked to filter out eroneous data. Well rugosity, a measure of the integrity of the formation adjacent to the well has a huge influence in determining the credibility of the recorded data. The caliper $\log$, which measures the deviation of well diameter from drit bit diameter (rugosity) was used to determine the sections of the sonic log to despike. Despiking was carefully done to prevent removal of vital information.

Check-shot survey data which helped to put the bit on the seismic section by providing accurate time/depth correlation were also quality checked (Halliburton, 2017). A very simple data QC approach was adopted. The general data trend was identified and those that plotted outside this trend were filtered out, especially where there is no geological justification for the 
off plot. The $\mathrm{QC}$ was done on individual wells and found to be more effective than handling the entire field's check-shot in a single pass.

\subsection{Sonic calibration}

Sonic calibration involves bringing the time of the sonic log into agreement with seismic times from a check-shot data (White and Simm, 2003). This is because there often exit variation between the seismic times obtained by the sonic log and that of the check-shots, due to reasons such as cycle skipping, invasion, formation alteration as well as error associated with mud arrivals in large holes (Serra, 1984). The despiked check-shot times were used to calibrate the sonic log through a process known as drift curve correction. The drift curve, a log of the difference between the sonic log and the checkshot seismic time was adjusted until minimum separation between the sonic and the check-shot seismic times was obtained.

\subsection{Synthetic seismogram generation}

The quality of the generated synthetic seismogram with which to effectively tie the well to the seismic section depend much on the quality of the wavelet which act as the source function with which to convolve the generated reflectivity function obtained from the acoustic impedance log derived from the calibrated sonic and the density logs. Zero phase, minimum, positive and negative (normal and reversed polarity) Ricker wavelets, having length of $128 \mathrm{~ms}$ and central frequency of $35 \mathrm{Hertz}$ were extracted from the seismic data around the reservoir using deterministic wavelet extraction technique (Ricker, 1944; Wang, 2015). The extracted wavelets were employed to generate initial synthetic. The seismogram that gave the best correlation with the seismic data as well as that which requires minimum bulk shifting for good tie with the seismic data was accepted. The TDR between the initially generated synthetic seismogram and the seismic data was used to adjust/bulk shift the well appropriately to place the well logs on the seismic section.

Finally, the obtained TDR from the generated synthetic seismogram was then used to convert the depth calibrated well data (well tops) to seismic time domain and thus employed to tie the seismic data to wells by post- 
ing the well top accurately on the seismic record of Wytch Farm for the identification of hydrocarbon saturated horizon reflection events.

\subsection{Fault interpretation}

Fault interpretation which involves delineation of structural discontinuity in seismic reflection events was carried out using extracted seismic variance attribute in addition to the convectional tracing of abrupt termination of coherent reflection events. Seismic variance attribute is apt at enhancing coherence and linear features, it is an edge detection technique commonly employed to enhance fault. The variance attribute was used to identify major faults which are continuous and extends almost through the entire field. The time slice variance attribute was also employed to guide the fault mapping especially where the resolution of the seismic record becomes too low (poor) and the faults were barely visible. The faults were picked on the in-lines seismic sections which run parallel to the general geological trend of the field. The idea is that faulting, especially the dip-slip fault is likely to run perpendicular to the general geologic trend of the field and thus the discontinuities will be more visible on the in-line sections. Abrupt termination of coherent seismic reflection events and continuation across the fault plane (either up-or down thrown depending on whether normal or reversed) guided the vertical extension of the fault plane.

\subsection{Horizon mapping}

Horizon mapping involved tracing the continuity of the lithological boundaries which correspond to the formation tops posted on the seismic section. Six (6) horizons corresponding to the formation tops (Top Chalk, Top Greensand, Combrash, Mercia Mudstone, Top Sherwood and Base Sherwood) were mapped. The Top Sherwood and the Base Sherwood correspond to the top and base of the reservoir of interest in this study. These formations were earlier delineated from well log data and cores as oil bearing from previous petrophysical study of the field (outside the scope of this study) and thus selected for further hydrocarbon potential evaluation of the field. The reflection horizons having the right polarity with the formation tops were traced both on the seismic in-lines and the cross lines sections. The 
polarities of the horizons were maintained during the tracing, except for cases of polarity reversal which rarely occurred. Horizon mapping took into consideration the horizon displacement minding the degree and direction of throw (up or downward) across dip-slip faults. Flipping the seismic record from the colour coded section to wiggle trace, variable density or a combination of the two helped resolved some ambiguities where the resolution of seismic record becomes poor. The tracing was initially done at 20 steps within the lines and latter at much finer step of ten. The close or misties around loops indicate level of accuracy. A close loop between the in-lines and cross lines suggests a properly traced horizon on both lines.

The Top Greensand horizon was the first to be mapped, mainly because of its strong and visible reflection that maintained fairly visible amplitude throughout nearly all the lines. The Top Chalk horizon, the first from the top, was not well represented on the land seismic record, only well preserved on the marine part of the seismic sections. Consequently, the Top Greensand was bulk time shifted upward by $302 \mathrm{~ms}$, and the horizon adjacent to the bulk shifted surface was mapped across the field. This is based on the fact that the top of the Greensand coincide with the base of the Top Chalk. Thus knowing the time difference between the two adjacent formation tops, (average 2-way time difference determined from previous Wytch Farm field report), bulk time shifting was applied to identify the Top Chalk horizon which is poorly imaged on the land section of the seismic data. The top of Combrash and Top Mercia Mudstone were subsequently mapped. The horizon corresponding to the Top Sherwood also presents weak seismic reflection, displaying varying amplitude and shows numerous discontinuities. This is likely due to the low acoustic impedance contrast between the Mercia Mudstone and Top Sherwood. This made the mapping of the horizon very tricky. After some attempts to trace the Top Sherwood horizon which produced poor surfaces, the bulk time shifting approach was also adopted. The Mercia Mudstone was bulk-shifted downward by $179.5 \mathrm{~ms}$ (average 2-way time difference between the Mercia Mudstone and Top Sherwood) and the horizon adjacent to the bulk-shifted surface was mapped as the Top Sherwood. Similar approach was adopted to map the Base Sherwood, whose reflection suffered similar fate as the Top Sherwood. The Top Sherwood was bulk shifted by $77 \mathrm{~ms}$ and the horizon around the bulk shifted surface was mapped. 
The picked horizons were checked for quality (QC) to ensure that there is neat tie around the loops and that the same event was traced throughout the lines as corresponding to the same horizon. Portions with mistie around loops and where reflections appear in different times were selected and corrected until satisfactory tie was achieved.

\subsection{Velocity model for time-depth conversion}

Domain conversion from time to depth is a very critical aspect of geophysical seismic data interpretation, it enables the conversion of various information obtained in time, such as the generated formation surfaces and fault polygons into depth. This is important since exploratory decisions are usually based on actual depth and not time, where the geometry of the reservoirs and the thickness of the pay are better appreciated. Several velocity model analyses exist and attempts were made to generate different velocity models using all the available methods. The method that offered the most geologically reasonable and geophysically plausible model was adopted. The $V_{0} K$ and the $V_{I N T}$ interval velocity model analyses presented geologically reasonable results, while the $V_{I N T}$ gave the best model that was used for time-depth conversion. The adopted model is a layer cake model that makes $V_{0}$ correction constant, where $V_{0}$, the surface velocity, is kept $K$ constant. The generated velocity model was subsequently used to convert the generated surfaces and the fault polygon from time to depth, thus converting the structural depth map of the horizon of interest into depth structure map.

\subsection{Gross Rock Volume (GRV) determination}

The essence of seismic interpretation is often to evaluate the volume of hydrocarbon within the reservoir. The volume of rock mass saturated with oil is essential for the determination of Stock Tank Oil Initially In Place (STOIIP) and this was obtained by estimating the volume of hydrocarbon bearing rock mass above the Oil Water Contact (OWC). The area extent of the reservoir rock mass adjudged to be hydrocarbon saturated is usually defined by the structural closure, which in the case of Wytch farm is the fault assisted roll over anticlinal structures. 


\subsection{Interpretation uncertainties}

Several uncertainties were associated with different stages of interpretation of the Wytch Farm seismic record which could affect the integrity of the obtained interpretation results. Though concerted efforts were made to get round some of the different challenges encountered during the interpretation of the Wytch Farm field data, as discussed in the sections above, it is important to mention these challenges which may contribute to uncertainties in some of the results. For example, the check shot data where present did not perfectly agree with the sonic log data, this therefore generates large drift during calibration. The poor resolution of the seismic events corresponding to the top and base of Sherwood also affected the quality of the synthetics generated around the reservoir. Uncertainties associated with fault mapping can be linked with the challenges encountered in extending the fault stick (plane) downward as a result of reduction in resolution of Wytch Farm seismic record with depth, especially around the reservoir. Here the termination and continuity of events/horizons across the fault planes is rarely visible and very difficult to trace, sometimes never too sure where to put the fault plane, especially below the Mercia Mudstone. Furthermore, resolution challenge arises where the land and the marine seismic data were merged. This is because Wytch Farm seismic data volume combined land, transition and marine seismic data sets, acquired using different source and receiver types, i.e. dynamite and geophone on land to air gun and hydrophone in the marine environment. The merging of these differently acquired data sets to generate a single seismic volume presented some complexities in terms of data continuity and resolution. This made the tracing of reflection events across the seismic data corresponding to different environment quite difficulty and subject to error.

\section{Results and discussion}

The various results obtained at different analyses stages carried out to interpret the Wytch Farm seismic record for the hydrocarbon potential evaluation of the field are presented in this section. The generation of synthetic seismogram in order to tie well data to the seismic data for ease of posting well tops on seismic section for horizon mapping required despiking of the 
spurious data from the sonic log data and subsequently calibrating the sonic $\log$ with available check shot data. Figs. 3a,b present sections of the sonic log that were despiked based on well rugosity information provided by the caliper log. Sections of the sonic log where the well diameter deviate from the bit size gave low quality data that were characterised with some spurious readings, especially since the sonic logging tool records accurate information when the sonde carrying the transmeters and recievers is perfectly mounted against the wall of the borehole. This may be challenging where the well

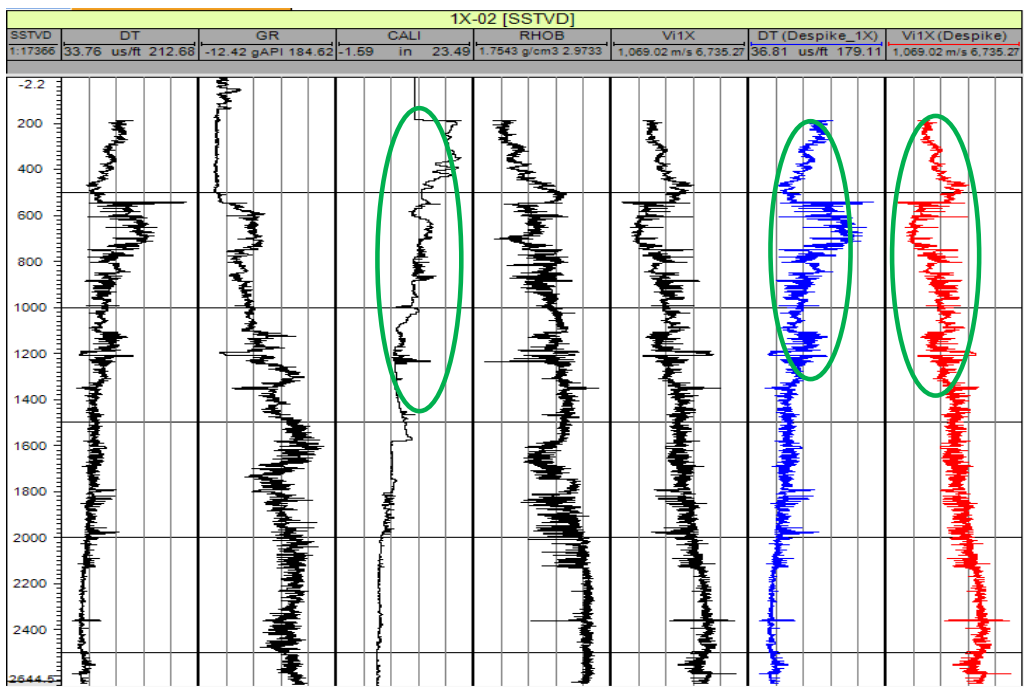

(a)

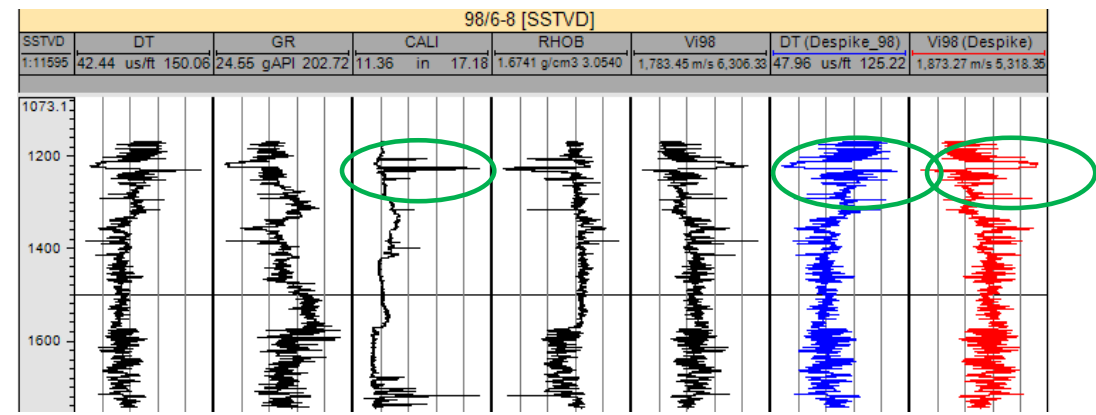

(b)

Fig. 3. Sonic and Caliper log of well $1 \mathrm{X}-02$ and 98/6-8 showing despiked section of the sonic $\log$ with the corresponding caliper plot which indicate well rugosity. 
is rugous and the integrity of the tool to accurately measure Interval Transit Time (ITT) may be compromised. Therefore removing spurious data recorded at this section helped improved the Signal to Noise $(\mathrm{S} / \mathrm{N})$ of the whole data and hence the resuting synthetics.

The QC of the check shot velocity data also ensured the removal of data that plot away from the general increase in velocity with depth trend. These off plot data are likely noisy data and removing them improved the $\mathrm{S} / \mathrm{N}$ ratio of the data. A plot of average velocity (check-shot) against depth which shows the trend from a single well, the despiked result as well as the result of the entire field's QC check-shot data are presented in Fig. 4a,b.
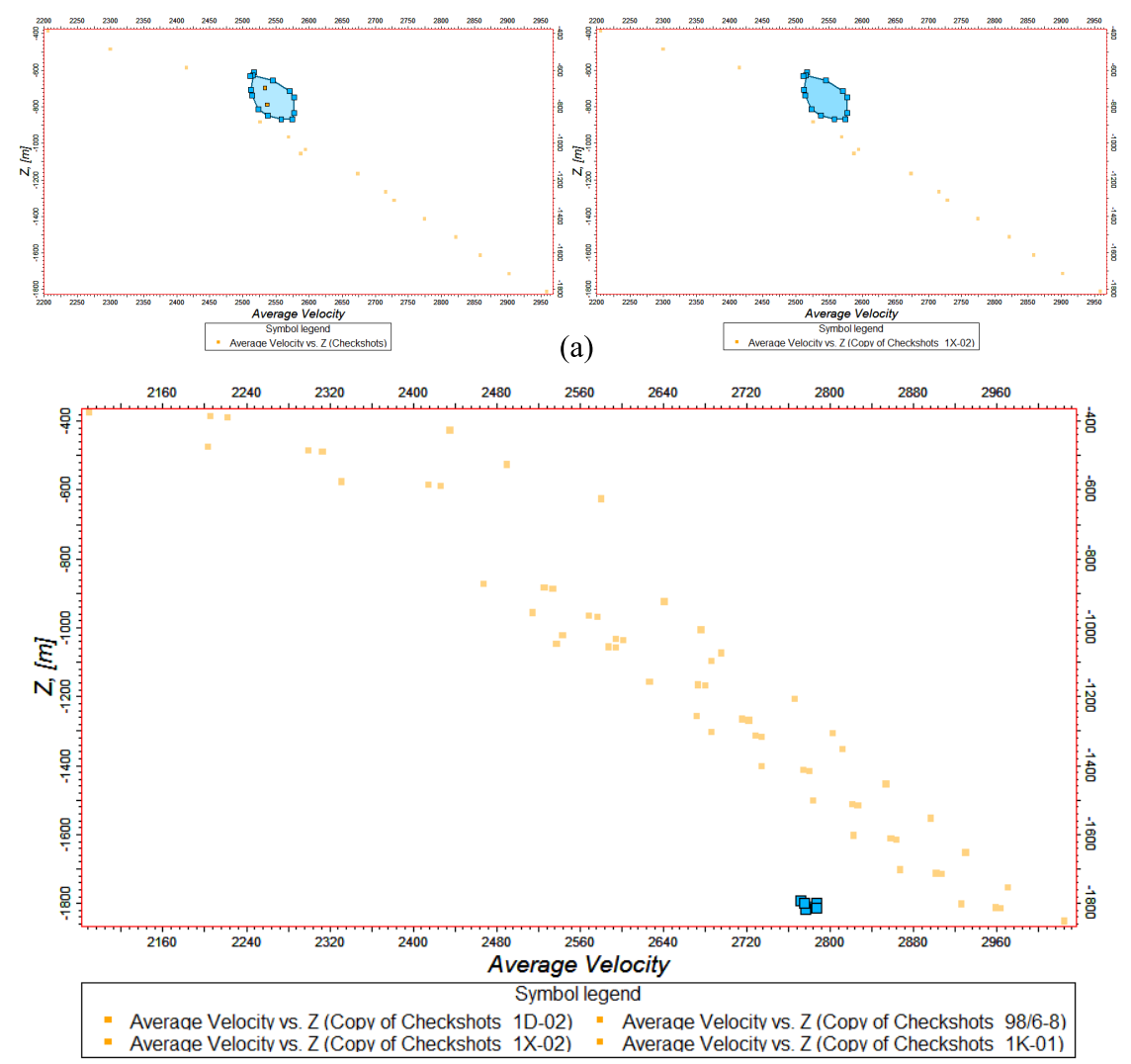

(b)

Fig. 4. Plot of average velocity (check-shot) against depth of single well check-shot trend showing removed data (a), the despiked result of the entire field's check-shot data (b). 
The calibration of sonic log data with the check-shot data to bring the sonic time into agreement with seismic times from the check-shot data is presented in Fig. 5 indicating minimum drift between the sonic and the check-shot data (first panel). The calibration generated fairly accurate and continuous sonic data beyond the limit of the sonic data and the resulting calibrated ITT employed to determine the interval velocity that was used to generate acoustic impedance log for synthetic seismogram.

The generated zero phase negative Ricker source wavelet with which the derived acoustic impedance logs was first convolved in order to generate initial synthetic seismogram is presented in Fig. 6. The real and accurate zero phase, negative source wavelet extracted from the Wytch Farm seismic record, generated using the initial TDR derived from the initially generated synthetic seismogram as guide, is presented in Fig. 7. The various generated synthetic seismogram shows positive correlation between the strong reflections on the seismic section and the synthetics (Fig. 8). The synthet-

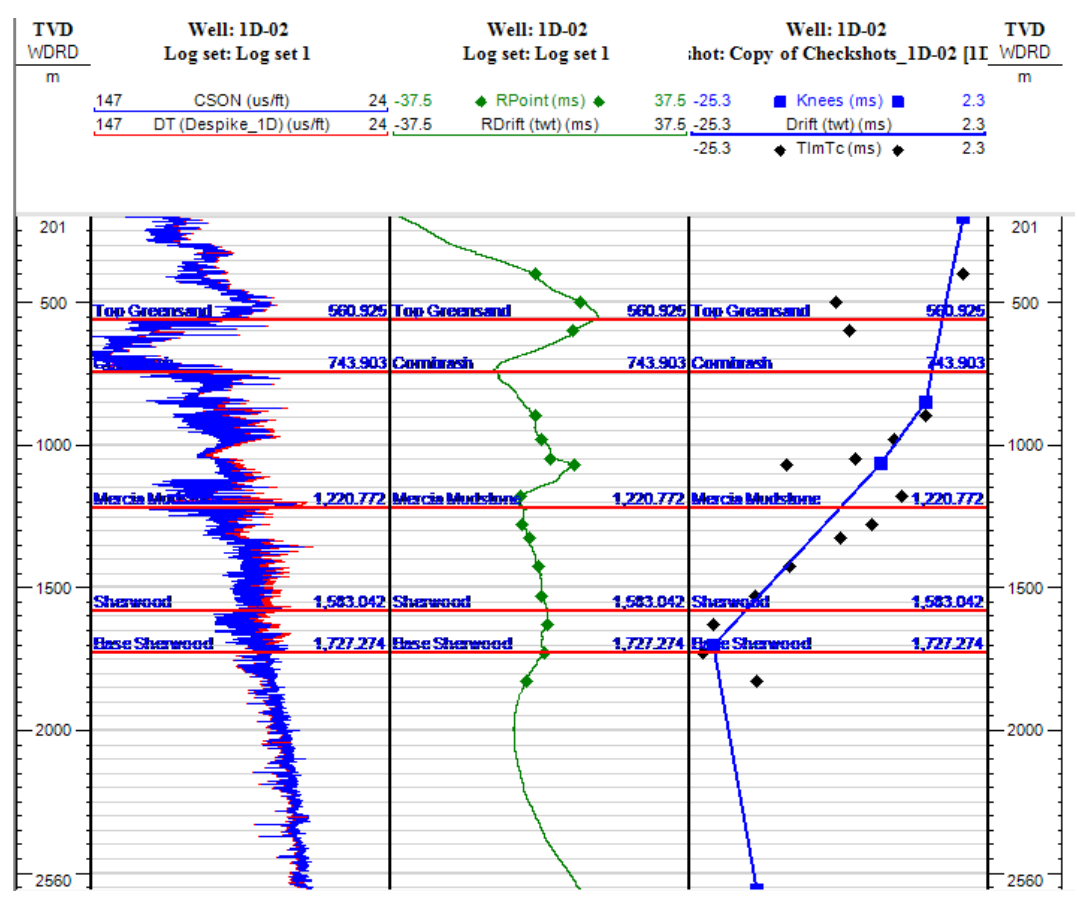

Fig. 5. Calibration of Well 1D-02 sonic log data using well Check-shot data. 

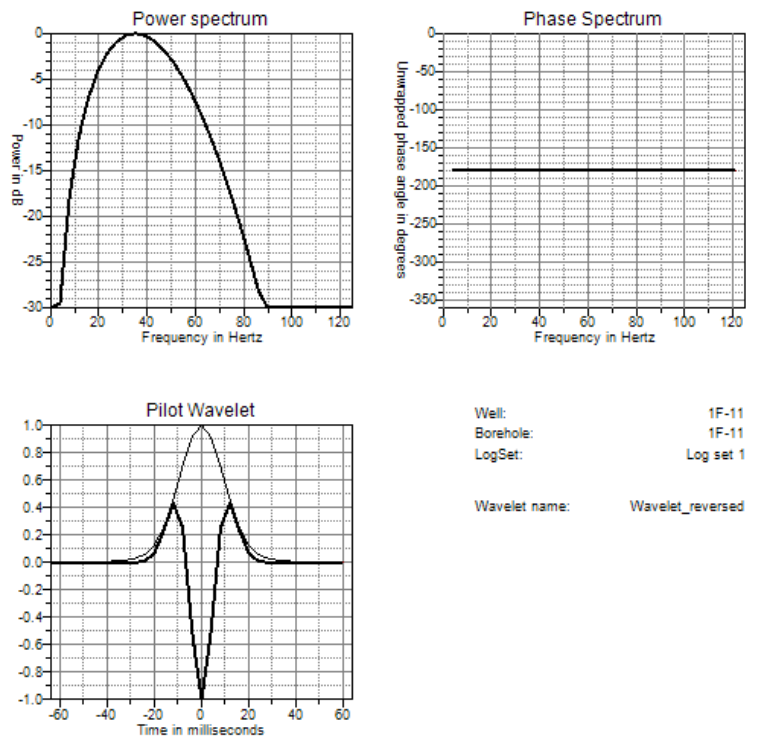

Fig. 6. A zero phase negative Ricker wavelet used to generate initial TDR.
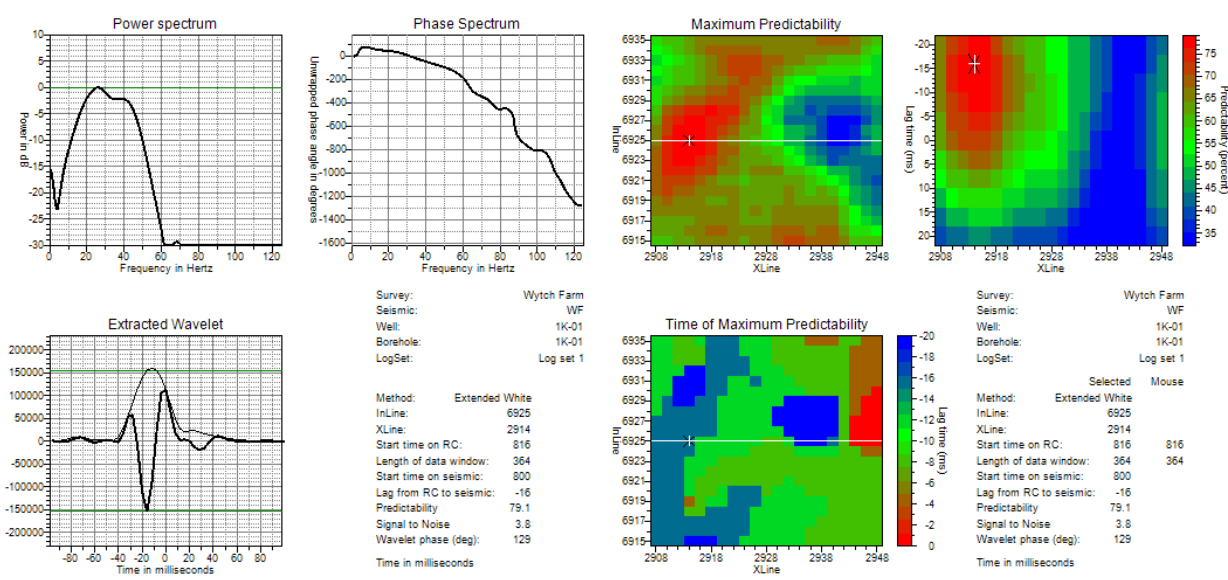

Fig. 7. Extracted wavelet (negative, near zero wavelet) around well 1K-02 using deterministic extraction method.

ics seismogram indicate a predictability value higher than 75 and Signal to Noise $(\mathrm{S} / \mathrm{N})$ ratio in excess of 3.

The synthetic seismograms generated around the reservoir from some of the wells' data are presented in Figs. 8a-c. The generated seismograms show 


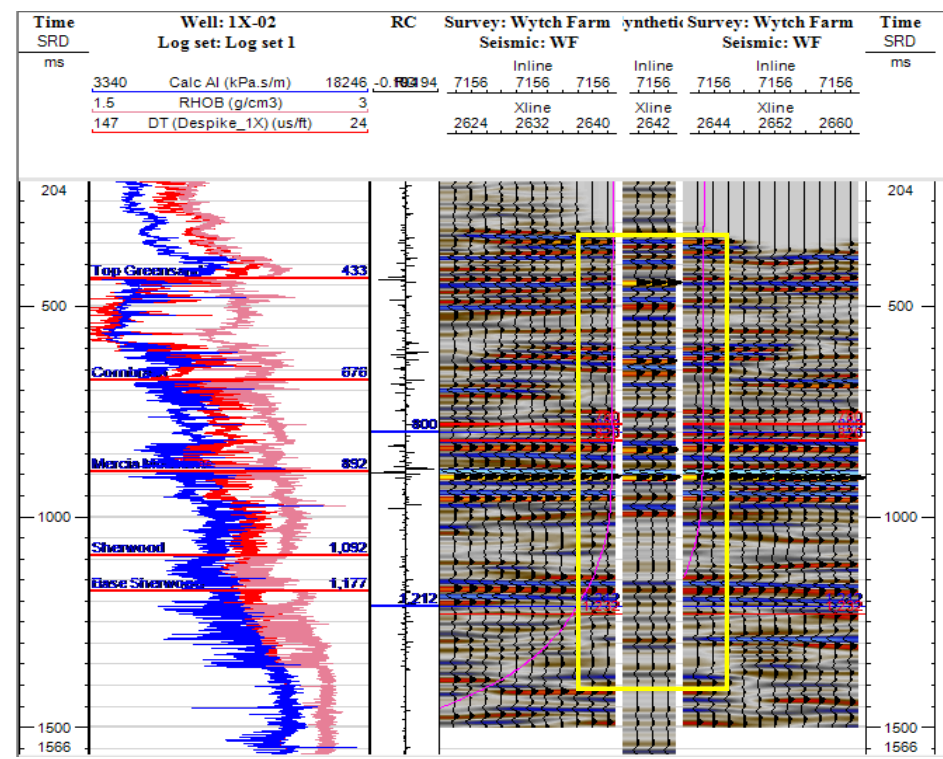

(a)

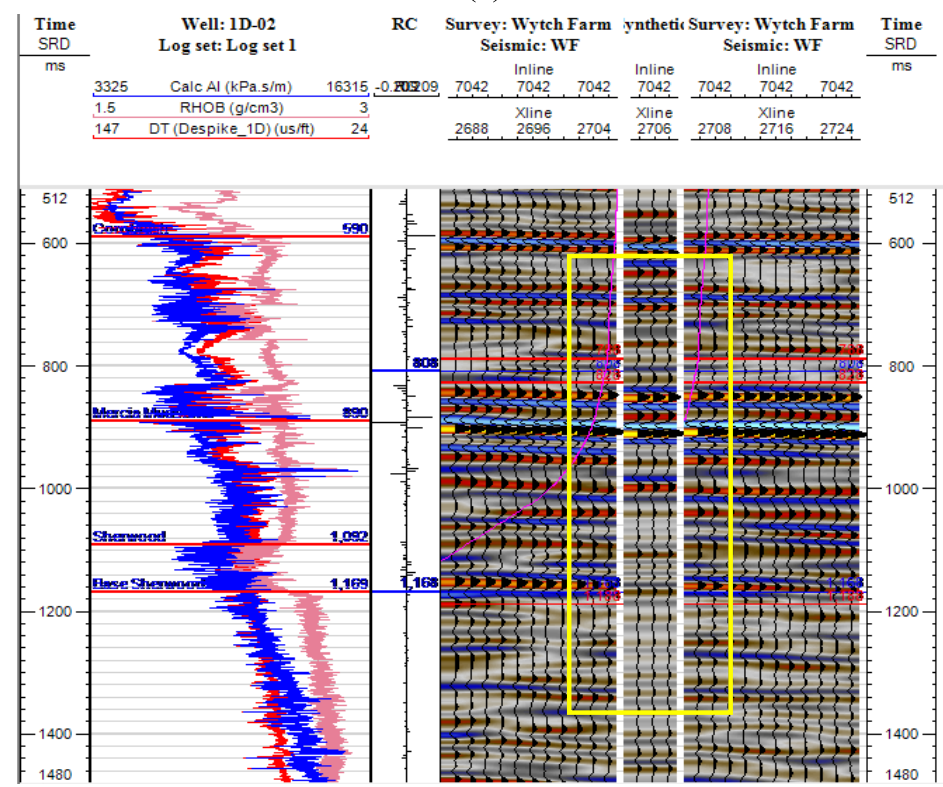

(b)

Fig. 8. Continuation on the next page. 


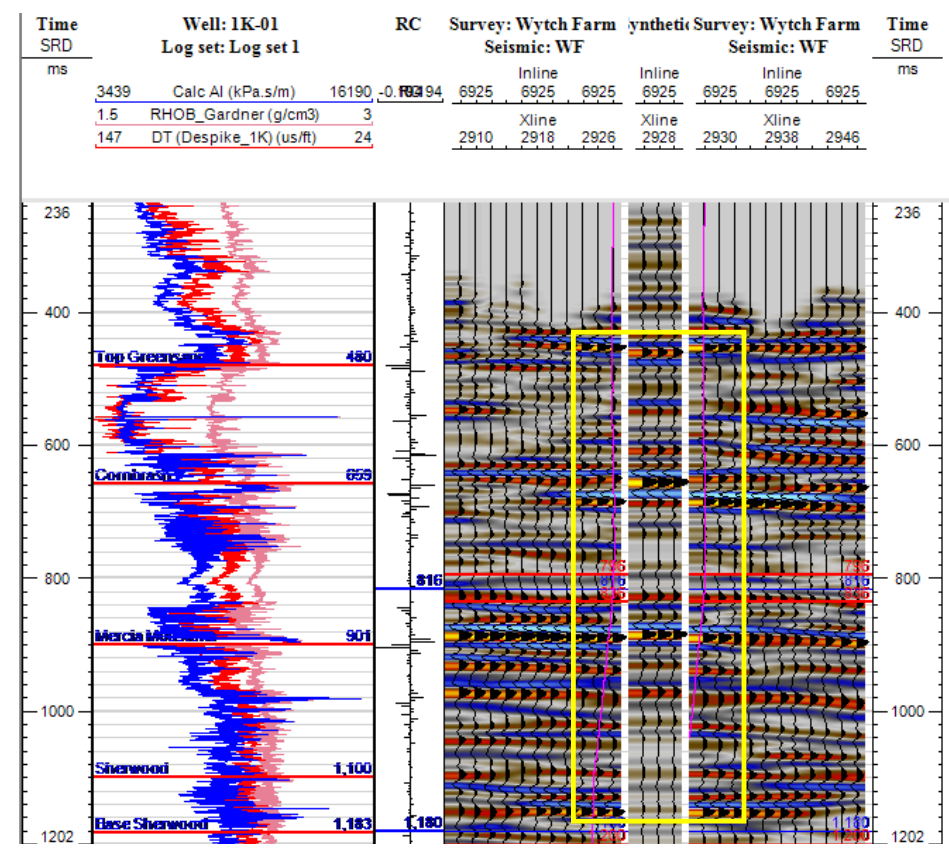

(c)

Fig. 8. Generated synthetic seismogram from wells 1X-02, 1D-02 and 1K-01 (a-c) respectively, showing positive correlation between the generated synthetic and the seismic record around the wells.

positive correlation between the well data and the seismic record. The positive correlation is clearly visible at the upper section of the well, especially around Top Greensand, Combrash and Mercia Mudstone that have strong reflections. However, subtle but positive correlation is observable around the Top and Base Sherwood.

Posted well tops from different wells appeared relatively accurate in time and displaying the corresponding formation's polarity (Fig. 9). The posted well tops indicate the top of Greensand, Combrash, Mercia and Sherwood (top and Base) Formations which presented negative (peak), positive (trough), European polarities respectively.

\subsection{Fault interpretation}

Mapped structural features presented as discontinuity in coherent reflection 


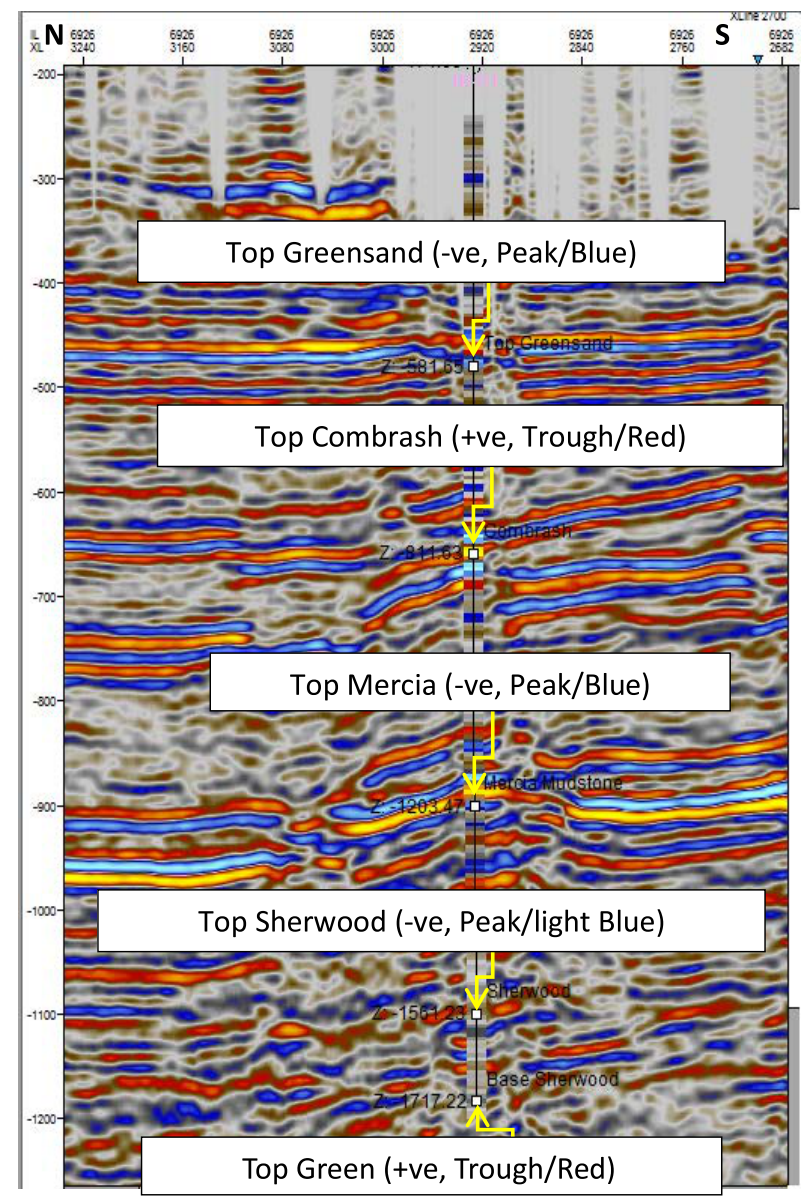

Fig. 9. Display of the generated synthetic seismogram and well tops (1k-01) on the seismic section, indicating a good seismic to well tie.

events on the Wytch Farm seismic record identified normal and antithetic faults. Some of the mapped fault planes are linear, while others have curvilinear geometry. Some of the faults have large throws while others suffered little vertical displacement. Twenty seven (27) faults were picked in all, the picked faults have fair continuity, but only six were considered major because they traversed the entire length of the field. Fig. 10a is the time slice of the variance attribute of the Wytch Farm seismic volume with lines of low coherence shown as dark linear features guiding fault mapping. Fig. 10b on 


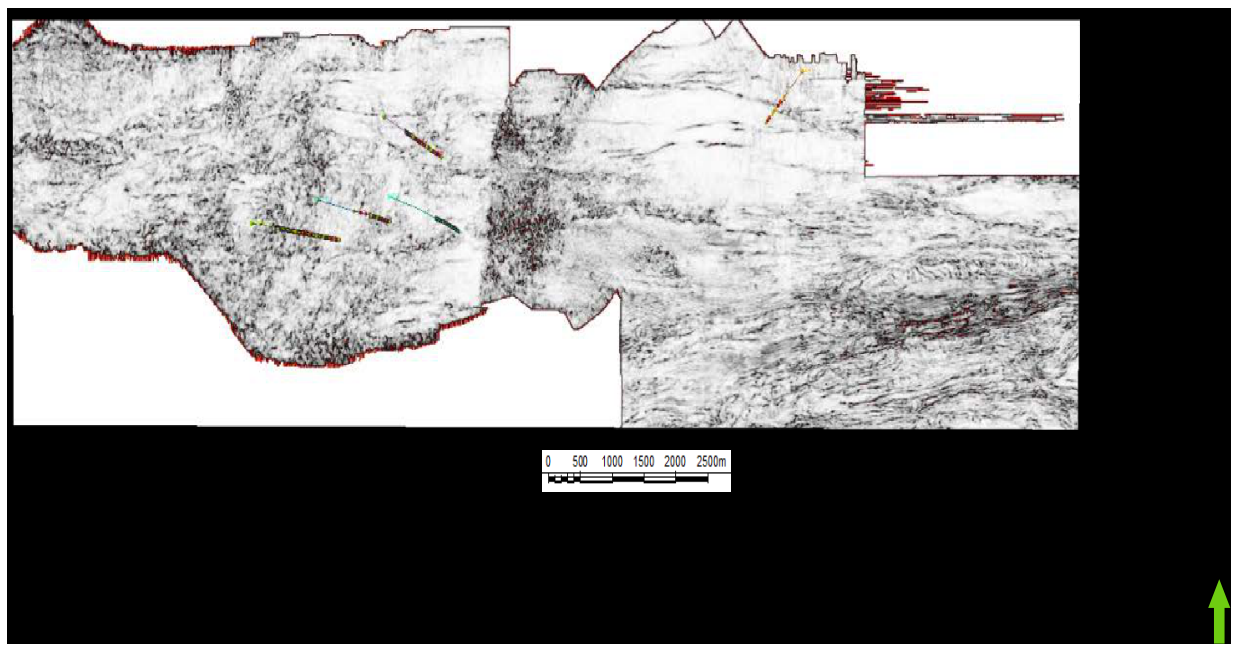

(a)

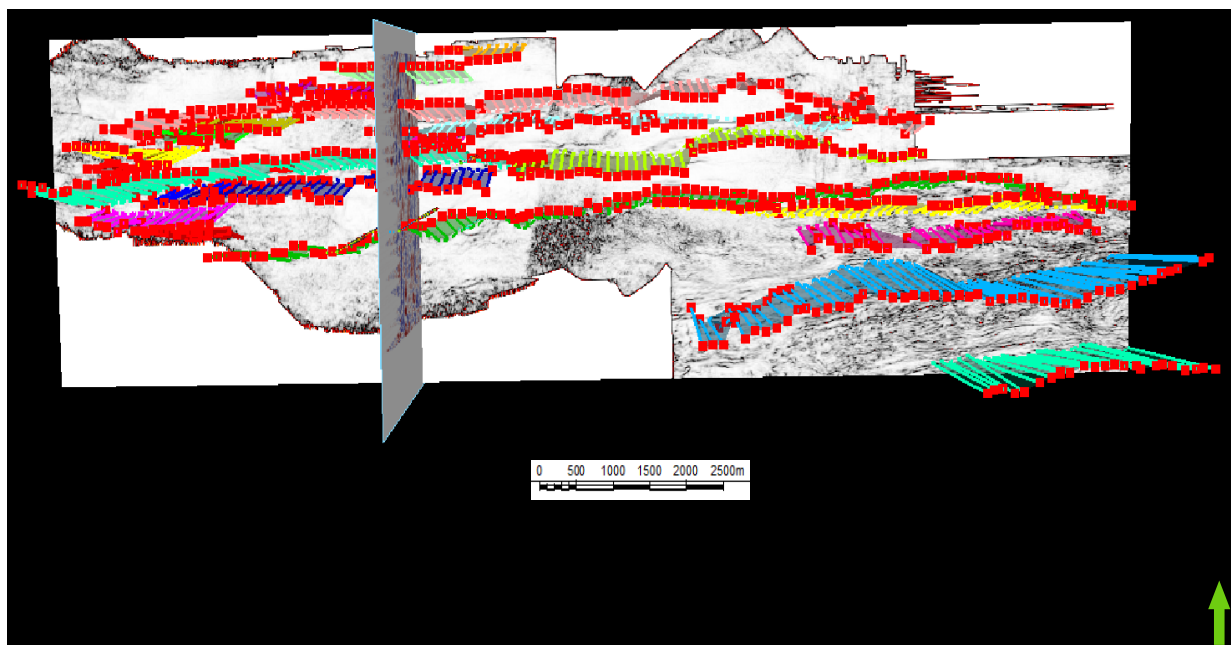

(b)

Fig. 10. Time slice of the variance attribute of the Wytch farm seismic volume (a), mapped faults on the time slice of Wytch farm variance attribute (b).

the other hand shows some of the mapped fault on the variance attribute map, which follows the direction of least coherence of the reflection events, thus indicating planes of discontinuities. Fig. 11 presents the fault interpreted seismic in-line section showing the delineated faults. 


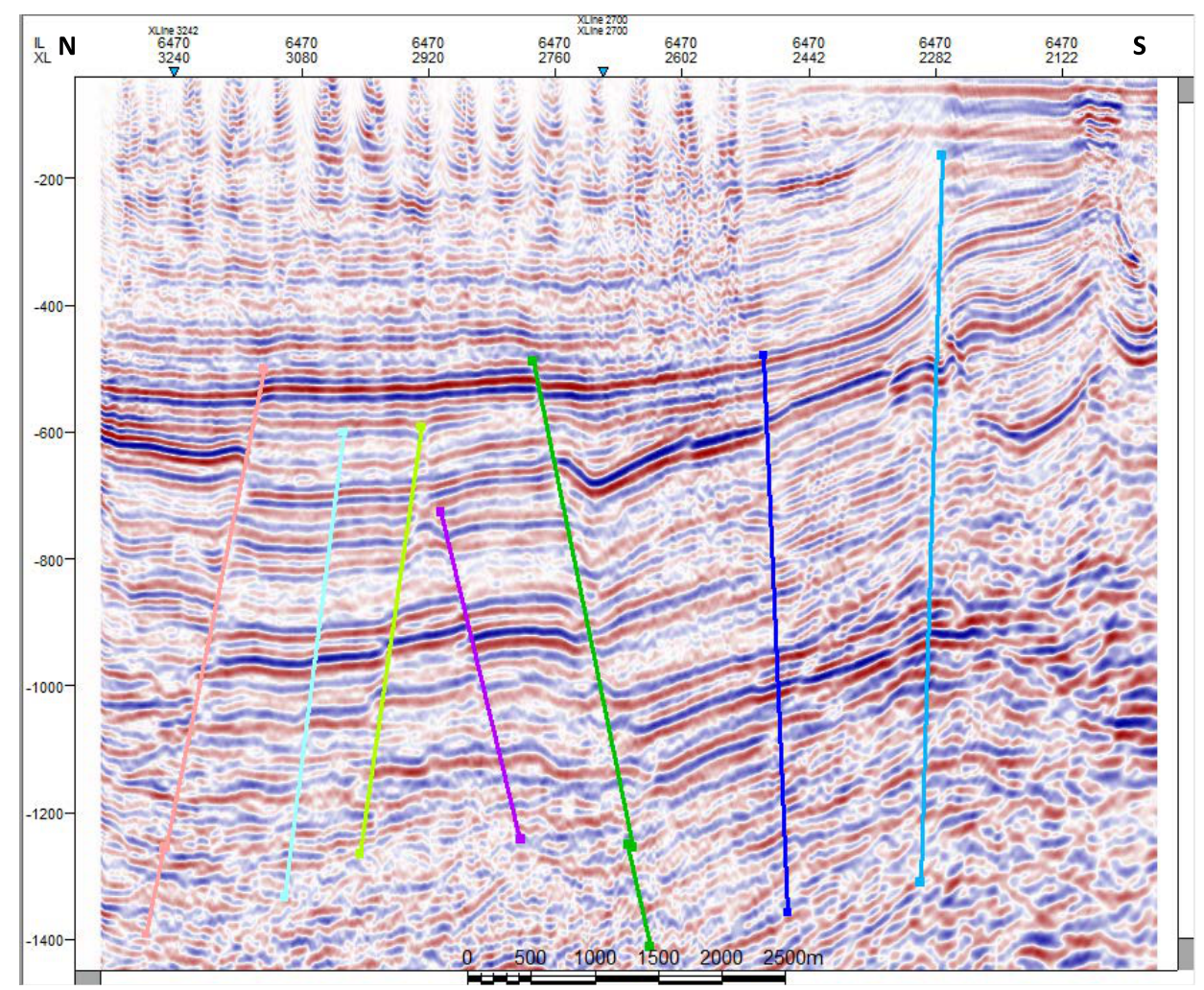

Fig. 11. Seismic in-line sections showing some mapped faults.

The horizon mapping which involved tracing each of the posted formation well tops along and across the in- and cross-lines, respectively, defined five (5) horizon surfaces which correspond to the top of Greensand, Combrash, Mercia Mudstone as well as the top and base of Sherwood Formations (Fig. 12). The top and the base of Sherwood Formation were traced because Sherwood is the reservoir of interest in this study. The horizons surfaces revealed the behaviour of the top of the mapped horizons. The generated horizons surfaces as well as the individual mapped surfaces in 3D view are presented in Figs. 13a,b.

The time map of the Sherwood reservoir which presents the smoothened contours generated from the plot of different Two Way arrival Times (TWT) of a horizon (seismic reflector) at the in- and cross-line intersections around 


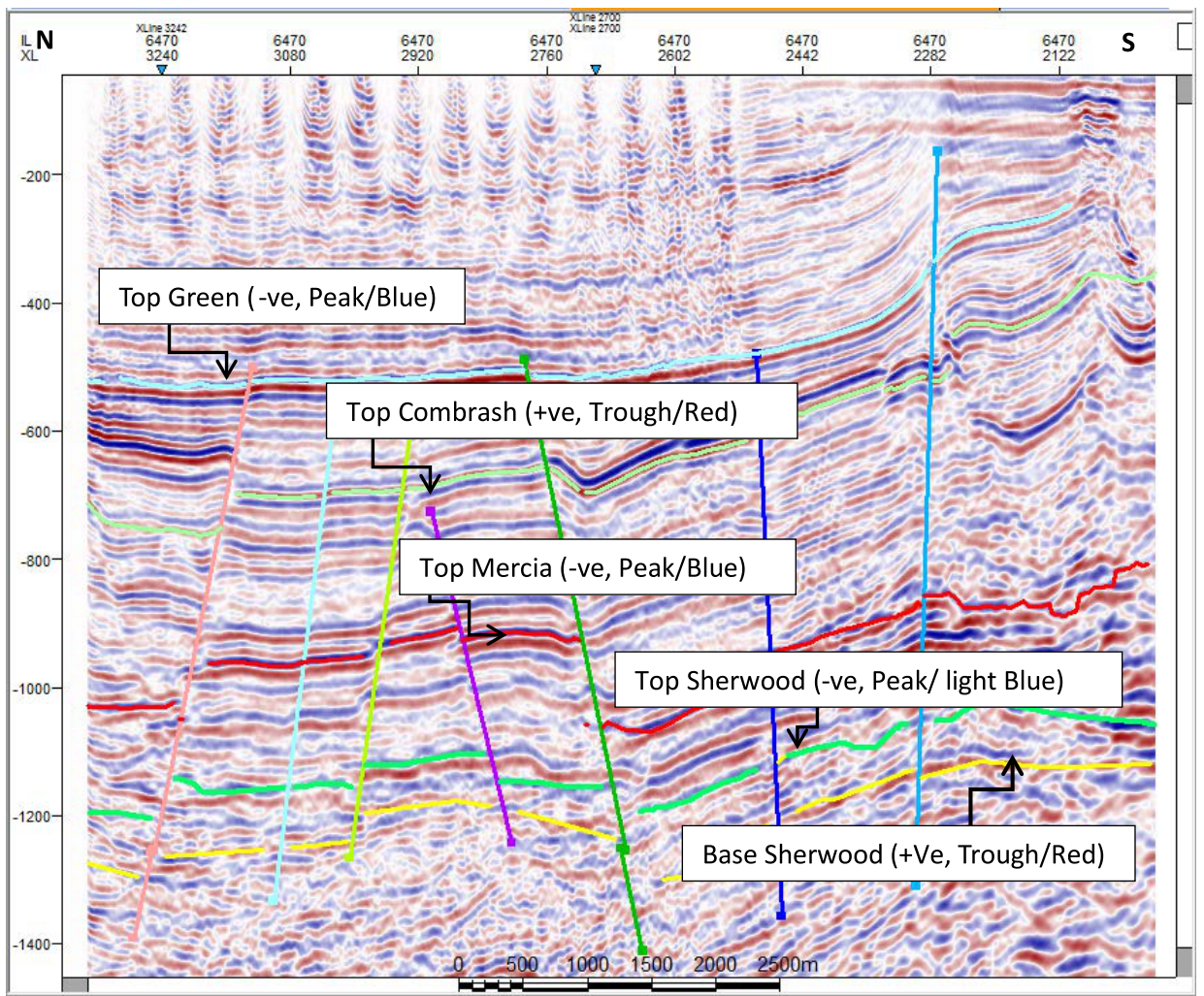

Fig. 12. Interpreted seismic in-line seismic section showing mapped faults and horizons.

loops are presented in Fig. 14. The map showed the structural contours in time of the Sherwood horizons. Five (5) major structural closures are visible on the time map, many of whose contours closed around the major faults.

The various formation surface velocities $\left(V_{0}\right)$ obtained for the different horizon surfaces and the generated velocity model using the layer cake earth model approach for the conversion of the generated time map into depth map are presented in Fig. 15. Fig. 16 presents the depth map of the Sherwood horizon. The map indicates a faulted blocks horst system which forms some anticlinal structures having contours that terminate against the faults.

Fig. 17 is the depth surface map of Sherwood reservoir while Figs. 18a,b present the $3 \mathrm{D}$ view and orthogonal view of depth map of Sherwood with 


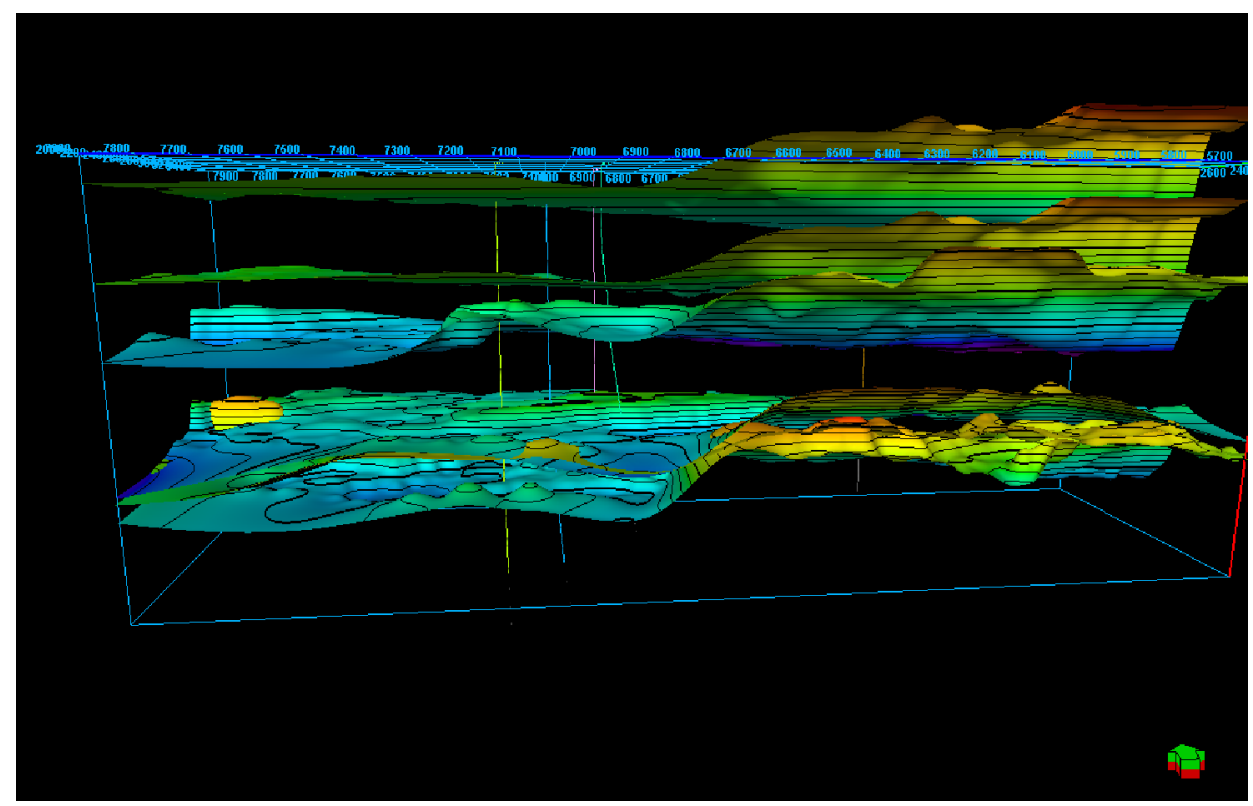

(a)

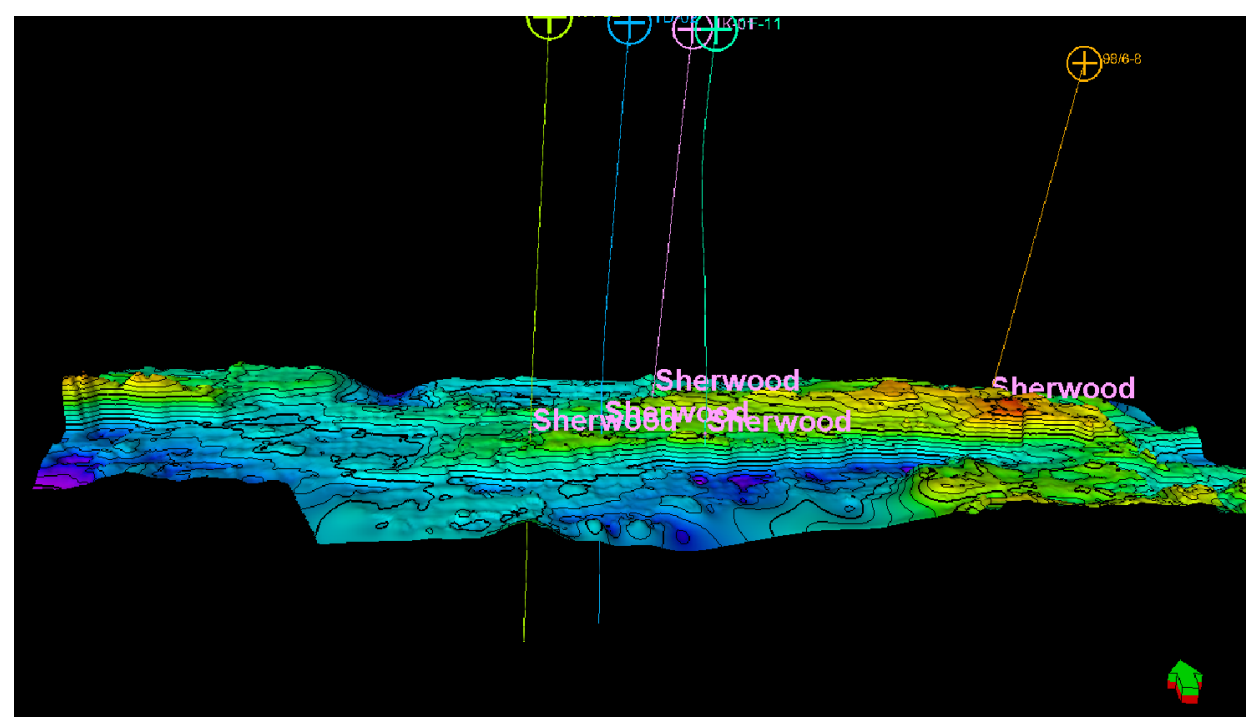

(b)

Fig. 13. Generated horizon surfaces (a), Sherwood Reservoir (b). 


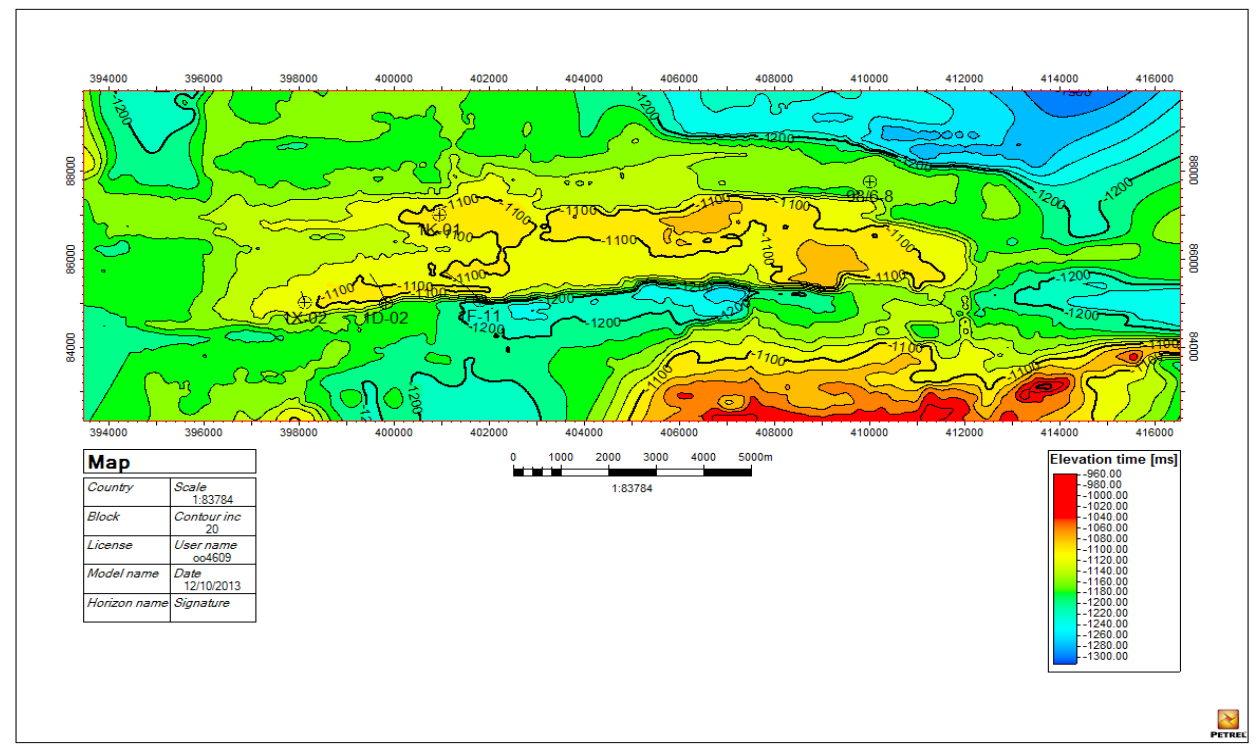

Fig. 14. Time map of Sherwood Reservoir.

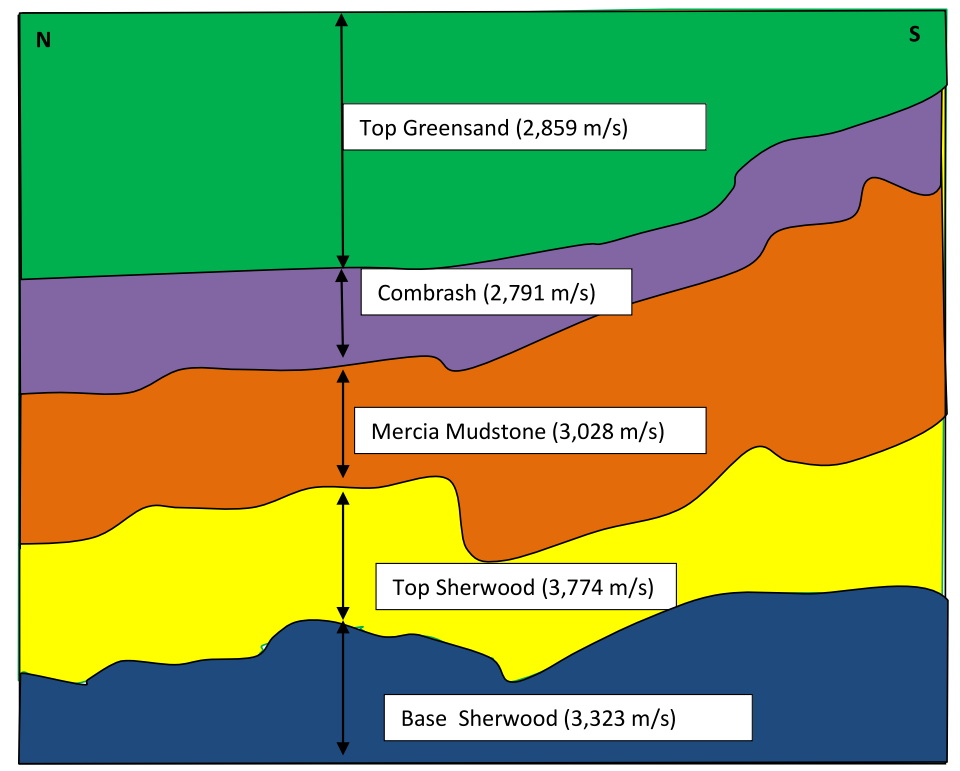

Fig. 15. $V_{0}$ values of various horizons surfaces obtained from velocity model analysis. 


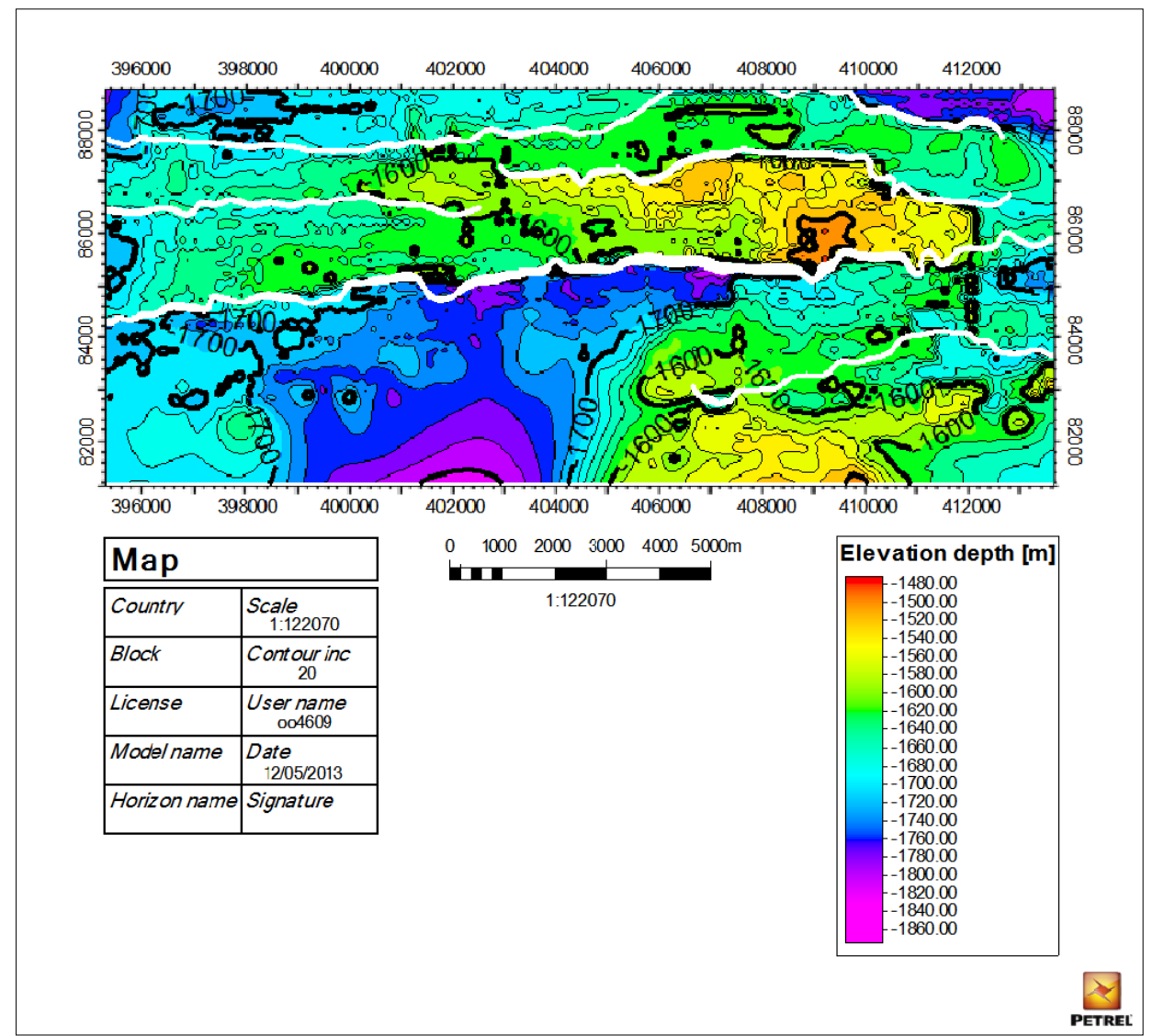

Fig. 16. Depth map of Sherwood Reservoir showing structural contours terminating against major faults.

OWC at a depth $-1624 \mathrm{~m}$ below the sea level. The OWC depth value which was determined from petrophysical analysis of the well log data is the blue platform above which the mapped horizon unit and structures lie. This enabled the ease of determination of the volume of rock above the water contact, which is the part of the reservoir saturated with hydrocarbon.

A fairly rectangular polygon inserted to define the reservoir boundary (3D view (Fig. 18a) and orthogonal view (Fig. 18b)) and employed to constrain the area extent of the reservoir area for GRV calculation generated a rock volume of $2,007,000,000 \mathrm{~m}^{3}$. 


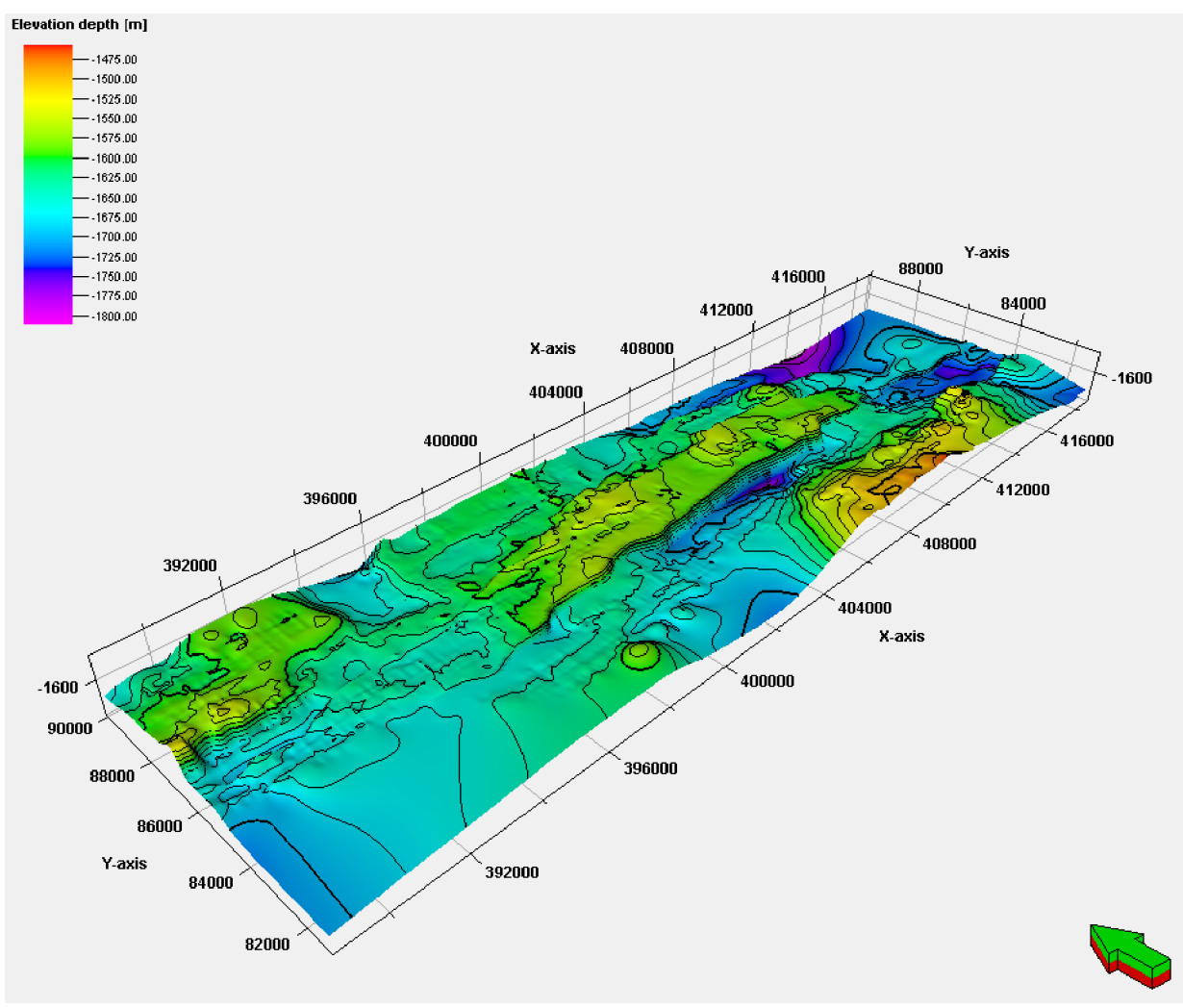

Fig. 17. Depth surface map of Sherwood Reservoir.

\subsection{Fault model and static geological model framework}

The generated fault model (Fig. 19) created using four (4) of the major delineated faults together with the mapped horizons were used to generate static geologic model framework of the Wytch Farm field (Fig. 20). The static geologic model framework integrates the delineated faults, mapped horizons, as well as additional lithologic information from analyses of available geological and production data, which are not presented in this study. The generated static geological model framework of the Wytch Farm field presents only the structural framework as well as the lithological distribution across the study area. It shows the various structural compartments that the field are divided into. It also indicates both the lateral and verti- 


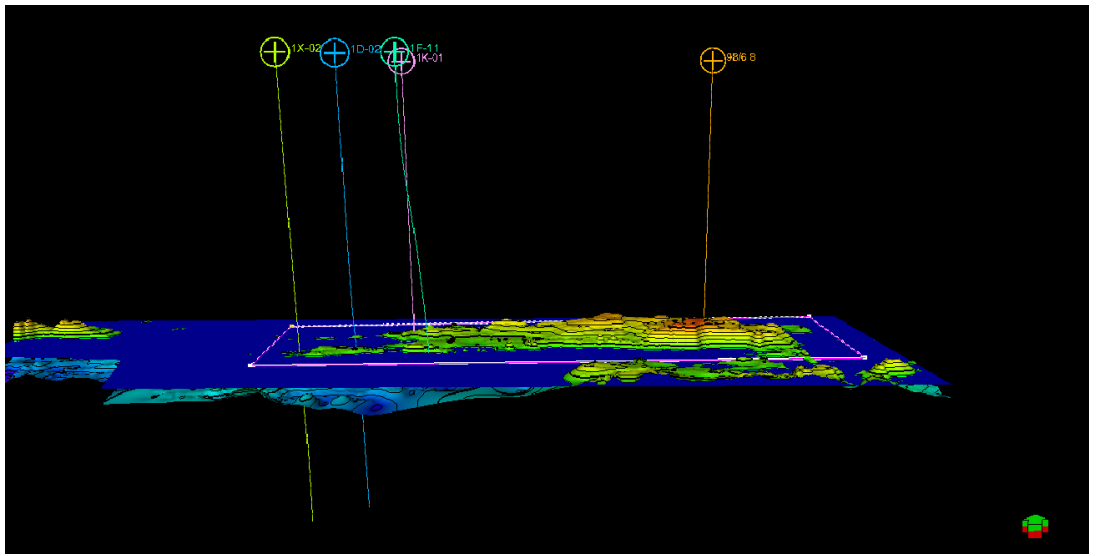

(a)

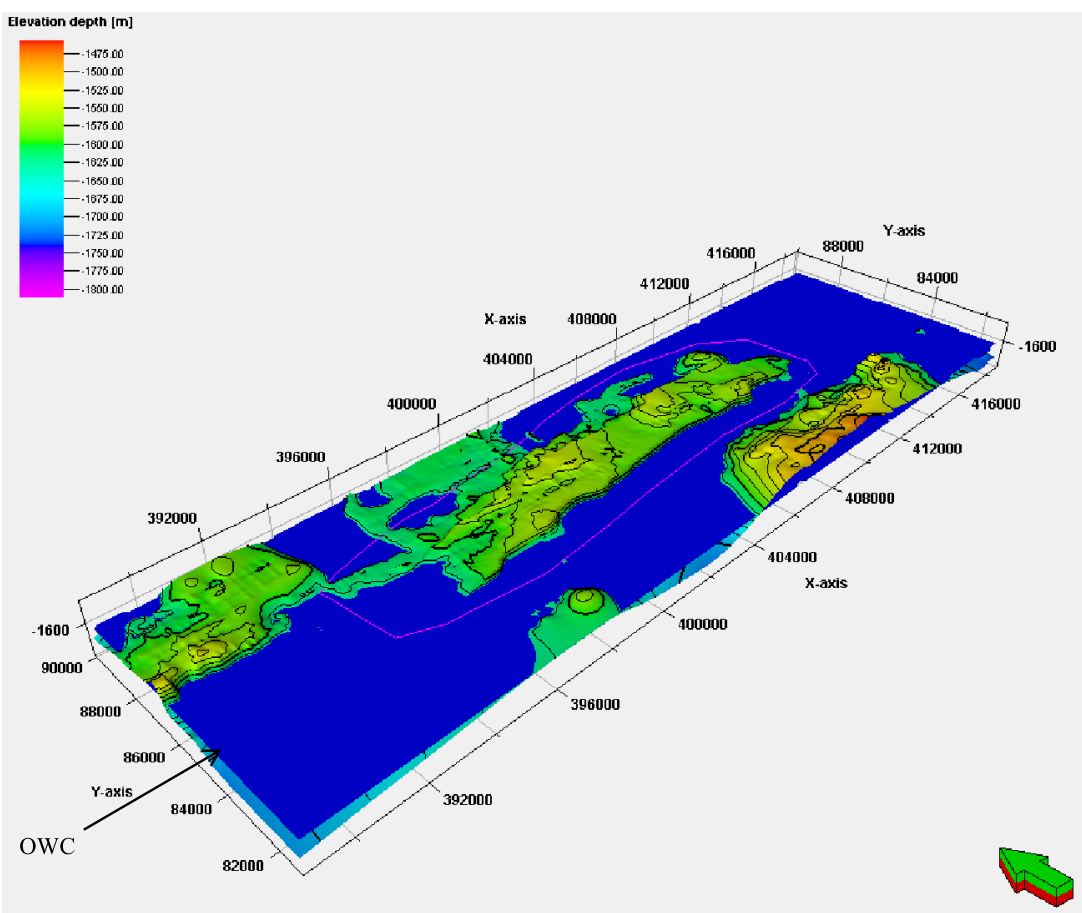

(b)

Fig. 18. Top Sherwood surface in depth with polygon and OWC to define the thickness and the area extent of oil saturated part of the reservoir $(\mathrm{a}-3 \mathrm{D}$ view and $\mathrm{b}-$ orthogonal view). 


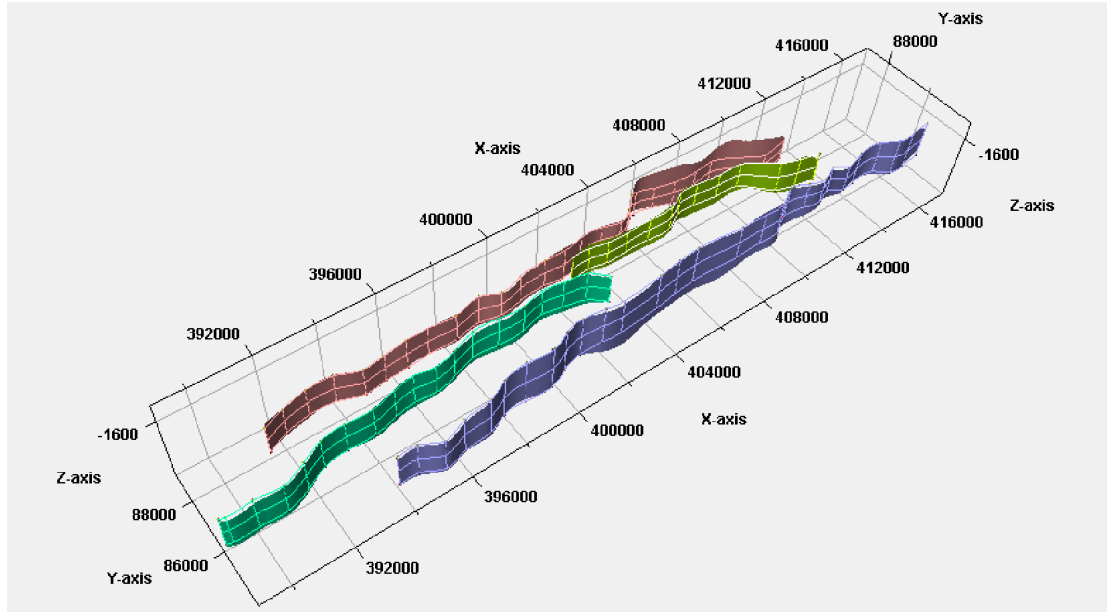

Fig. 19. Wytch Farm field reservoir model fault construction.

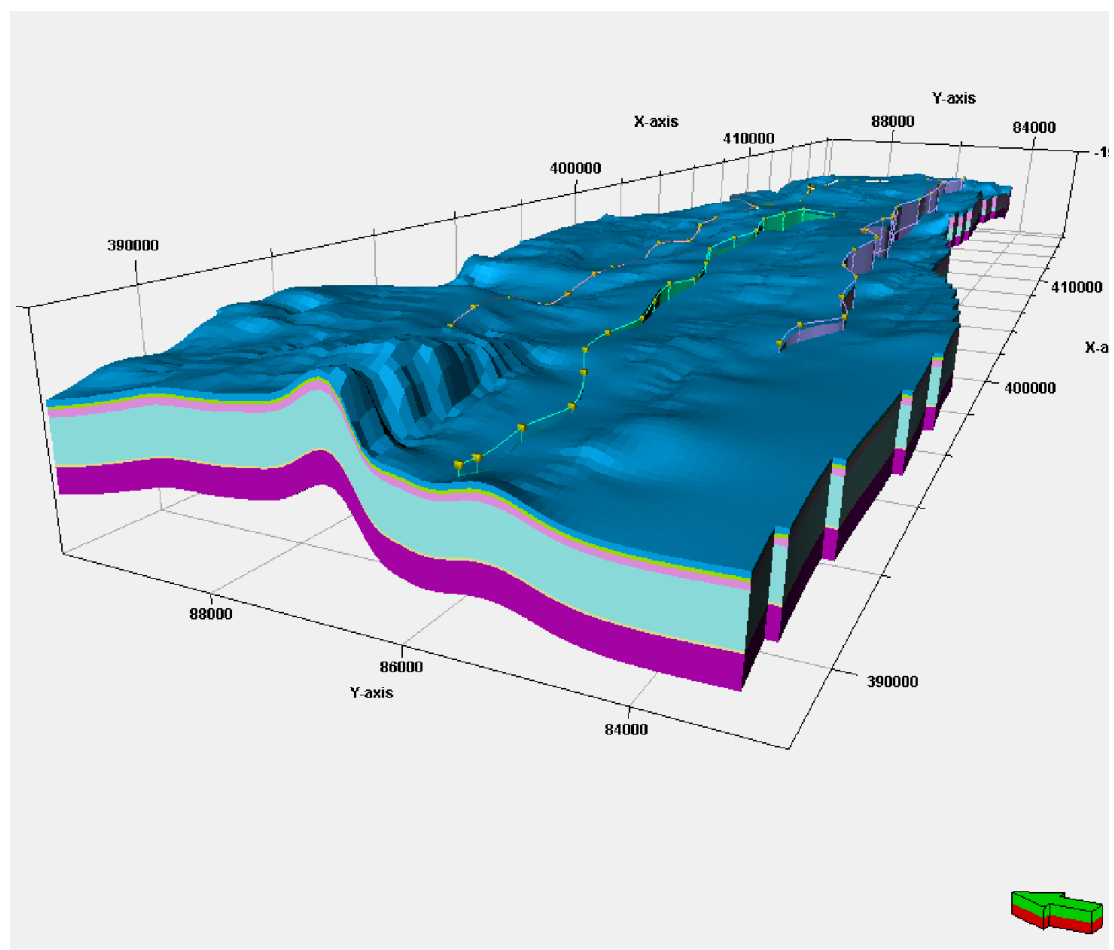

Fig. 20. Static geologic model of the Wytch farm field. 
cal distribution as well as association of the various rock units within and across the various structural compartments. The generated static geologic model framework offers a good platform for building and establishing the distribution and the behaviour of various petrophysical and production data such as facies distribution, porosity, permeability, hydrocarbon saturation among others. This platform therefore offers useful base for evaluating the field performance, establish reasons for early water breakthrough as reported, simulate various production scenarios to get round the problem and thus, flatten production decline curve and ultimately improve hydrocarbon production from the field.

\section{Conclusion}

This study has demonstrated that new idea with which to improve hydrocarbon production of a field could arise from revisiting, analysing and interpreting old existing subsurface data of the field. The study has also highlighted the data workflow for generating static geological model framework of the Wytch Farm field from existing old seismic and well log data which provide a good subsurface base useful for generating relevant reservoir management information requisite for improving field performance, especially to increase oil and gas production.

Acknowledgements. The author graciously acknowledges British Petroleum (BP), Perenco and their partners for generously donating Wytch Farm field dataset to Imperial College. The Department of Earth Science, Imperial College is also thanked for supplying the dataset for this study. The contributions of the anonymous reviewers, handling editor and indeed the entire editorial team of CGG are sincerely appreciated.

\section{References}

Arkell W. J., 1947: The Geology of the Country around Weymouth, Swanage, Corfe and Lulworth. Memoirs of the Geological Survey of Great Britain, England and Wales, H.M. Stationery Office, 386 p.

Beeley H. S., Norton M. G., 1998: The structural development of the Central English Channel High - constraints from section restoration. In: Underhill J. R. (Ed.): The Development, Evolution and Petroleum Geology of the Wessex Basin. Geol. Soc. Spec. Publ., London, 133, 1, 283-298, doi: 10.1144/GSL.SP.1998.133.01.13. 
Bowman M. B. J., McClure N. M., Wilkinson D. W., 1993: Wytch Farm oilfield: deterministic reservoir description of the Triassic Sherwood Sandstone. In: Parker J. R. (Ed.): Petroleum Geology of Northwest Europe: Proceedings of the 4th Conference. Geol. Soc., London, Petroleum Geology Conference series, 1513-1517, doi: $10.1144 / 0041513$.

Buchanan J. G., 1998: The exploration history and controls on hydrocarbon prospectivity in the Wessex basins, southern England, UK. In: Underhill J. R. (Ed.): The Development, Evolution and Petroleum Geology of the Wessex Basin. Geol. Soc. Spec. Publ., London, 133, 1, 19-37, doi: 10.1144/GSL.SP.1998.133.01.02.

Butler M., 1998: The geological history of the southern Wessex Basin — a review of new information from oil exploration. In: Underhill J. R. (Ed.): The Development, Evolution and Petroleum Geology of the Wessex Basin. Geol. Soc. Spec. Publ., London, 133, 1, 67-86, doi: 10.1144/GSL.SP.1998.133.01.04.

Colter V. S., Havard D. J., 1981: The Wytch Farm Oil Field, Dorset. In: Illing L. V., Hobson D. G. (Eds.):.Petroleum Geology of the Continental Shelf of North-West Europe. Hayden \& Son, London, 494-503.

Dearman W. R., 1963: Wrench-faulting in Cornwall and south Devon. Proc. Geol. Assoc., London, 74, 3, 265-287, doi : 10.1016/S0016-7878(63)80023-1.

Dingwall R. G., 1971: The structural and stratigraphical geology of a portion of the eastern English Channel. Rep. No. 71/8, Inst. Geol. Sci., London, 24 p.

Dranfield P., Begg S. H., Carter R. R., 1987: Wytch Farm oilfield: reservoir characterisation of the Triassic Sherwood Sandstone for input to reservoir stimulation studies. In: Brooks J., Glennie K. W. (Eds.): Petroleum Geology of North West Europe. Graham \& Trotman, London, 149-160.

Halliburton, 2017: Check-Shot Survey: Time/depth positioning puts the bit in the seismic section. H07887 7/17, Halliburton, https://www.halliburton.com/content/dam/

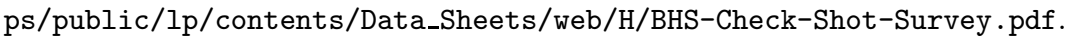

Hawkes P. W., Fraser A. J., Einchcomb C. C. G., 1998: The tectono-stratigraphic development and exploration history of the Weald and Wessex basins, Southern England, UK. In: Underhill J. R. (Ed.): The Development, Evolution and Petroleum Geology of the Wessex Basin. Geol. Soc. Spec. Publ., London, 133, 1, 39-65, doi : 10.1144/GSL.SP.1998.133.01.03.

Hinde P., 1980: The Development of the Wytch Farm Oilfield. Inst. Gas Engineers, London, Communication 1133.

Hogg A. J. C., Evans I. J., Harrison P. F., Meling T., Smith G. S., Thompson S. D., Watts G. F. T., 1999: Reservoir management of the Wytch Farm oil field, Dorset, UK; providing options for growth into later field life. In: Fleet A. J., Boldy S. A. R. (Eds.): Petroleum geology of Northwest Europe; proceedings of the 5th conference. The Geological Society of London, 1157-1172.

Johnson H. D, Fraser A. J., Hampson G. J., Jackson M. D., John C. M., Cosgrove J., Collier J. S., Sephton M. A., Jakubowicz H., Spathopoulos F., 2012: Petroleum Systems and Reservoir Characterisation in the Wessex Basin (southern England). A guide to field study in Wessex Basin Department of Earth Science and Engineering, Imperial College London. 
Mckie T., Aggett J., Hogg A. J. C., 1998: Reservoir architecture of the upper Sherwood Sandstone, Wytch Farm field, southern England. In: Underhill J. R. (Ed.): The Development, Evolution and Petroleum Geology of the Wessex Basin. Geol. Soc. Spec. Publ., London, 133, 1, 399-406, doi: 10.1144/GSL.SP.1998.133.01.21.

Morris J. E., 2005: Sedimentology, sequence stratigraphy and reservoir characterisation of the Bridport Sands. Unpubl. PhD thesis, University of London.

Ricker N., 1944: Wavelet functions and their polynomials. Geophysics, 9, 3, 314-323, doi: $10.1190 / 1.1445082$.

Serra O., 1984: Fundamentals of well-log interpretation. Elsevier Science Publishers, Amsterdam, Oxford, New York, Tokyo.

Smith A. J., Curry D., 1975: The structure and geological evolution of the English Channel. Philos. Trans. R. Soc. Lond.,A, 279, 1288, 3-20, doi : 10.1098/rsta.1975.0036.

Smith C., Hatton I. R., 1998: Inversion tectonics in the Lyme Bay-West Dorset area of the Wessex Basin, UK. In: Underhill J. R. (Ed.): The Development, Evolution and Petroleum Geology of the Wessex Basin. Geol. Soc. Spec. Publ., London, 133, 1, 267-281, doi: 10.1144/GSL.SP.1998.133.01.12.

Stoneley R., 1982: The structural development of the Wessex Basin. J. Geol. Soc., 139, 4, 543-554, doi: 10.1144/gsjgs.139.4.0543.

Strong G. E., Milodowski A. E., 1987: Aspects of the diagenesis of the Sherwood Sandstones of the Wessex Basin and their influence on reservoir characteristics. Geol. Soc. Spec. Publ., London, 36, 325-337, doi: 10.1144/GSL.SP.1987.036.01.23.

Underhill J. R., Stoneley R., 1998: Introduction to the development, evolution and petroleum geologyof the Wessex Basin. In: Underhill J. R. (Ed.): The Development, Evolution and Petroleum Geology of the Wessex Basin. Geol. Soc. Spec. Publ., London, 133, 1, 1-18, doi: 10.1144/GSL.SP.1998.133.01.01.

Wang Y., 2015: The Ricker wavelet and the Lambert W function. Geophys. J. Int., 200, 1, 111-115, doi: 10.1093/gji/ggu384.

Warrington G., Audley-Charles M. G., Elliot R. E., Evans W. B., Ivimey-Cook H. C., Kent P. E., Robinson P. L., Shotton F. W., Taylor F. M., 1980: A Correlation of Triassic Rocks in the British Isles. Special Report of the Geological Society, 13, London, Oxford, Blackwell Scientific, 78 p.

White R. E., Simm R., 2003: Tutorial: Good practice in well ties. First Break, 21, 10, $75-83$.

Zheng S. Y., Legrand V. M., Corbett P. W. M., 2007: Geological model evaluation through well test simulation: A case study from the Wytch Farm oilfield, southern England. J. Pet. Geol., 30, 1, 41-58, doi: 10.1111/j.1747-5457.2007.00041.x. 